\title{
The heart of the wood
}

\section{Białowieża is one of the best-preserved woodlands in Europe. But is it a good reference point for what Europe looked like 5,000 years ago? Emma Marris goes deep into the forest to find out.}

$\mathrm{n}$ dappled light, the trunks of lindens, Norway spruces, and oaks prise the undergrowth and the canopy apart. Quite a few are dead, and draped with beards of moss.

Birds sing in the cool, green-smelling air. It is very still, and at first feels almost timeless. But time is here - time past and time present. Hornbeam limbs, once weighed down with snow, are still bowed at oblique angles in the summer. Red deer bones on the ground mark an old kill; saplings clamber like children on the body of their recently fallen parent. As the wind ruffles the canopy, patches of sun traipse to and fro on the forest floor. Fat, desultory mosquitoes drift through the air.

Behind a shrub stands a European bison, or wisent, in the prime of his life, with curled black horns, a high woolly shoulder and a ridged backbone. He is browsing noiselessly. In a few minutes he will glide away as noiselessly as if he were slipping back 1,000 years to when his kind roamed forests like these over most of Europe.

The Białowieża forest in eastern Poland is a place apart, and of the past. Grey wolves hunt red deer; woodpeckers - all ten of Europe's species live here - hunt for beetles in 500-year-old oaks; stripy young boar splash through alder bogs blooming with yellow irises. The forest spreads over some 146,000 hectares in Poland and Belarus, various parts of it are managed in various ways, and have been cleared at various times. But it is said that the 4,438 hectares at its Polish core have never been cleared. Many of the forest's ecological processes have run uninterrupted since the last ice age, and the trees have never been selected for wood that can be sawn into long, knotless boards. It is thus a reference point, showing how humans have changed forest composition and processes elsewhere. It is a model for sylviculturalists interested in conservation - or in commerce, as tree plantations that mimic nature may produce more wood.

The University of Warsaw's Geobotanical Station and the Polish Academy of Sciences' Mammal Research Institute, both in Białowieża village, study the surrounding forest to get an idea of how things once were. The Mammal Research Institute is most famous for the discovery by one of its staff of the Dehnel effect, in which shrews actually shrink their skeletons to cope with reduced food supply in winter. The forest is indubitably a good place to study species in conditions most like those to which they were adapted. Ornithologists, in particular, love the forest and have noted that bird life there is diverse, but not dense; the reverse of what's seen in agricultural landscapes. But to what extent is Białowieża, as often claimed, Europe's last primeval broadleaf forest?

In his 1996 book Natural Woodland (Cambridge Univ. Press), the British naturalist George Peterken defines three types of naturalness. He contrasts "original-naturalness" - "the state which existed before people became a significant ecological factor" - with "present-naturalness", "the state which would prevail now if people had not become

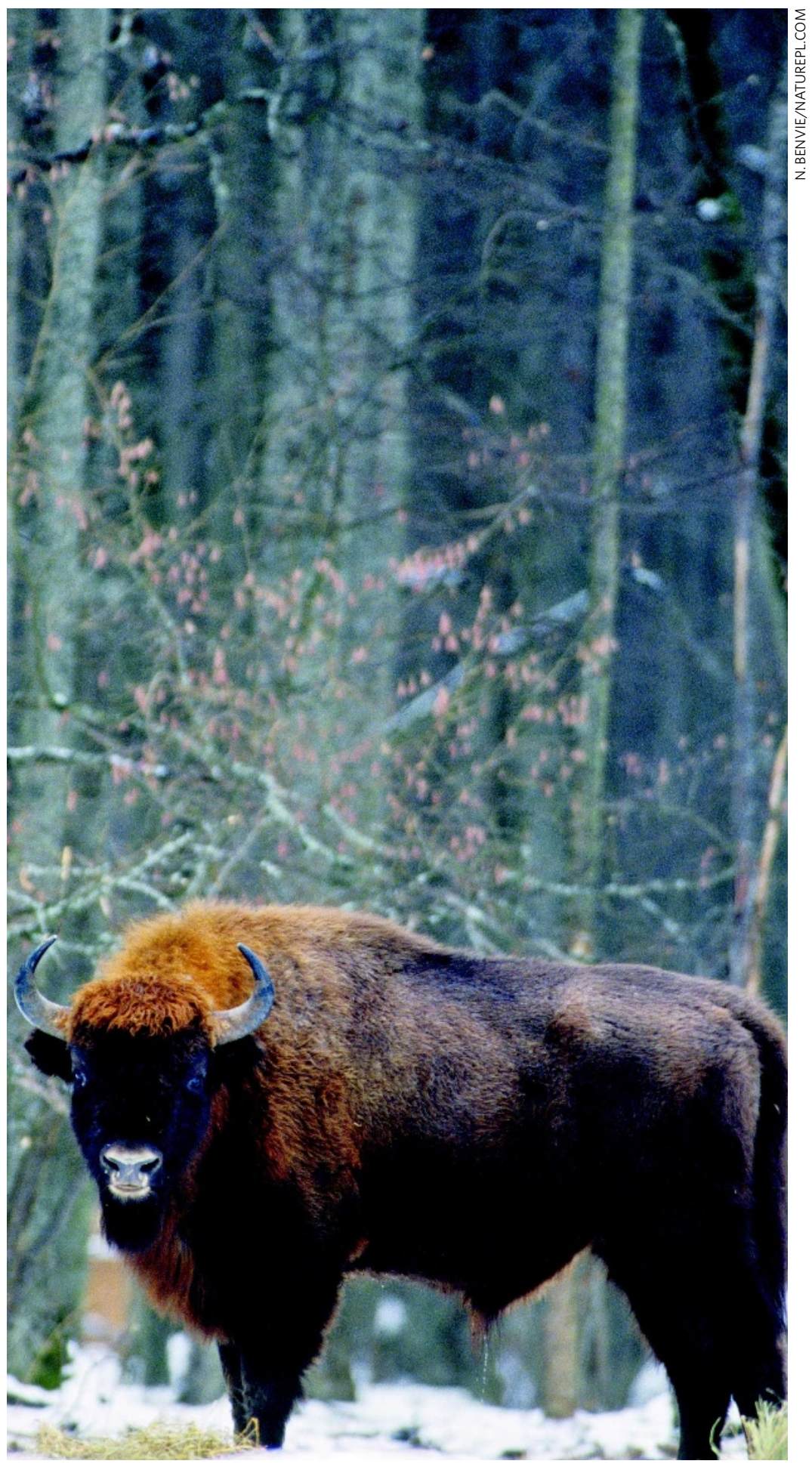




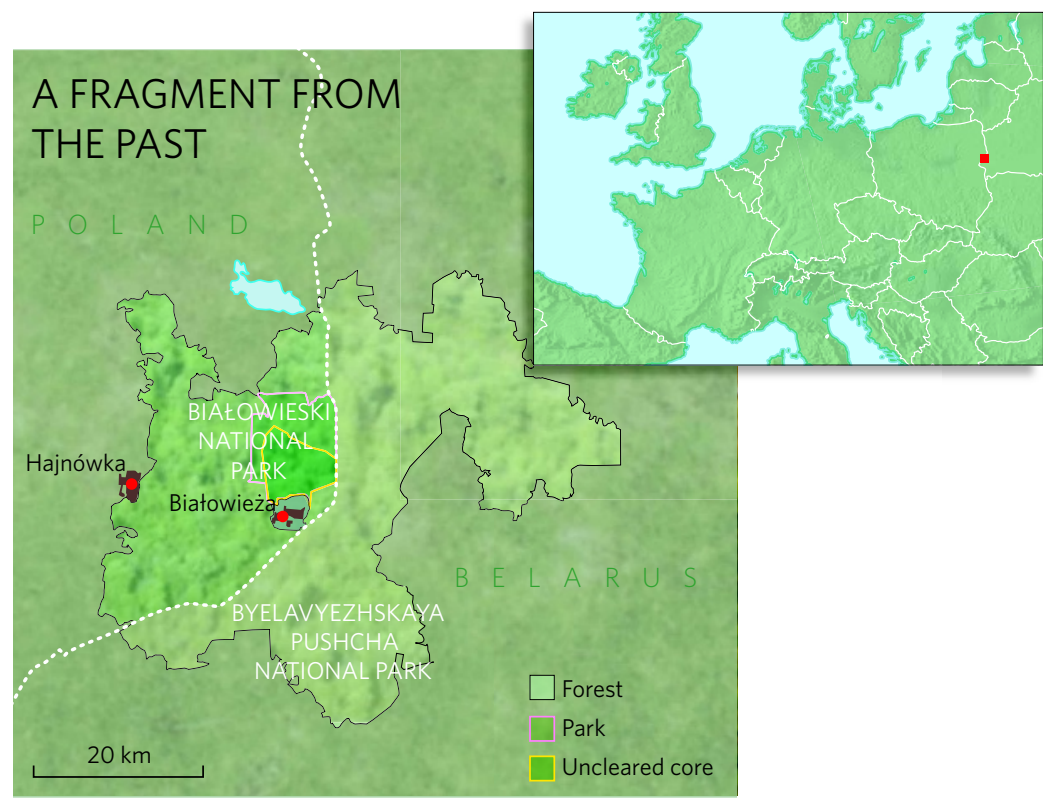

a significant factor". To see the difference, remember that forests are constantly shaped by fire and storm. In the clearing, seedlings compete for light. Trees fill in the gaps. Soil is depleted and fertilized; climate alters. A forest that has travelled thousands of years down a human-free road will change on the way, as original-naturalness becomes presentnaturalness. And both are distinct from "future-naturalness", "the state which would eventually develop if people's influence were completely and permanently removed".

Few environmentalists have adopted Peterken's distinctions. They prefer terms such as 'virgin' and 'old growth' forests, seeing the human factor as more crucial than any other. The problem with this, Peterken notes, is that if human use is taken in its broadest sense - not just logging - there is no more virgin forest in North America than there is in Europe. Native Americans managed their woodlands for game and maintained open spaces using fire.

\section{Royal playground}

Białowieża cannot aspire to present-naturalness. It owes its existence to the Lithuanian dukes, Polish kings, Russian tsars and German Nazis who kept it to themselves for hunting, first to feed their armies, later for sport. The forest ungulates were fed winter hay. Competing predators were killed; there are no more bears in Białowieża. The European mink that once flourished are also gone, their place now taken - apparently without much ecological disruption - by Asian raccoon dogs and American mink escaped from fur farms. Before they went extinct in the early seventeenth century, aurochs, the ancestor to domestic cattle, probably shared the forest with wisent and red and roe deer. An unknown poacher shot the forest's last wild bison in April 1919; today's are descended from 13 zoo bison, the descendants of which were reintroduced into the wild in the 1950s.

This history of intervention makes the forest's ecology hard to read. Take the recent reduction in Norway spruce. Their share of the woodland, says Bogdan Jaroszewicz, head of the Geobotanical Station, has halved since 1950. Some believe the spruce trees are disappearing because of climate change; the park is at the southern limit of the spruce's range. Others blame the spruce bark beetle, although its effects may be synergistic with, not alternative to, those of climate change. But Jaroszewicz points out that a century ago Russian royalty were breeding so much game in the woods that very few saplings survived to maturity. "There was almost no regeneration," he says. This intense browsing might have had a greater impact on seedlings more succulent than those of spruce. No one can guess whether the spruce would be declining without previous human intervention.

What then of the possibility of original-naturalness the primeval state preserved? This is certainly the pitch of Białowieża's growing tourist trade. Definitions of 'natural' or 'pristine' or 'primeval' forest typically include trees of many different ages coexisting and the presence of marker species dependent on old or dead wood - often mosses, lichens and fungi. Białowieża has all these characteristics. Trees age, die and rot where they fall, fuelling the life cycles of innumerable beetles, fungi, woodpeckers and, eventually, the next generation of trees. In Białowieża's core up to one quarter, by volume, of the wood above ground in each hectare is dead, compared with $2 \%$ in commercial stands.

\section{Strange forces}

People have interacted with Białowieża for millennia, but not necessarily as agents of change - their needs remained constant. Hunting has affected the numbers of large animals, but pollen records suggest that in terms of the species that make up the forest's main constituents, Białowieża has stayed fairly constant for millennia. Tomasz Samojlik, who grew up near the forest, has returned to study its environmental history at the Polish Academy of Sciences' Mammal Research Institute in Białowieża village. He has investigated royal hunts, beekeeping in trees, ore-smelting operations deep in the forest, and more. "After five or six years I have come to the conclusion that humans have always been connected to the forest," he says. For humans, he adds, the forest could be a matter of life and death: "They were part of it and could be killed by it easily." But for the forest, humans were one factor among many - they shaped it in some ways, left it alone in others, and were no threat to it at all.

That was then. "Now we are some strange force from an outside world," says Samojlik. All concerned want to limit that force's impact. The humans who now manage Białowieża struggle to do so in a way that leaves no fingerprints, aspiring, in Peterken's terms, to something close to the future-natural. Tourists may enter only when accompanied by guides. A fence, built in the 1930s to exclude domestic animals, now stands as a barrier between the domains of humans and the woods. Passing through sunny fields to reach a shaded gate into the forest, researchers mark the separation of realms by anointing themselves with mosquito repellent.

But future-natural takes more than a fence. The Geobotanical Station's records show rum goings-on over the past 50 years that look like the work of climate: plants flowering earlier, changes in annual distribution of precipitation, changes in snowmelt timing. In a world where today's saplings will experience an atmosphere containing twice as much carbon dioxide as their parents' generation, a human-free future-naturalness is not an option.

A local approximation to future-naturalness may 
1.4.

x)

(2) 3

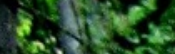

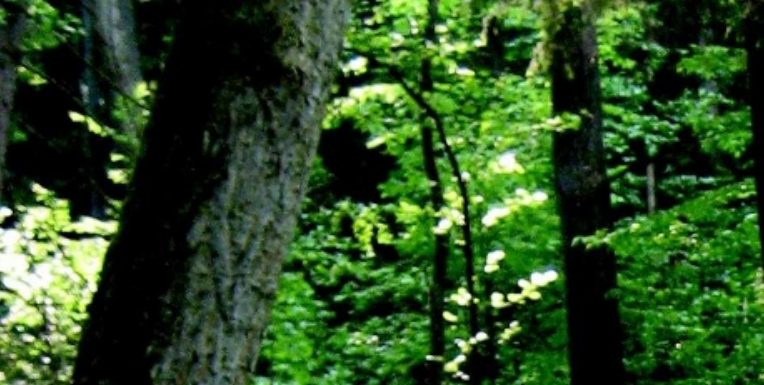

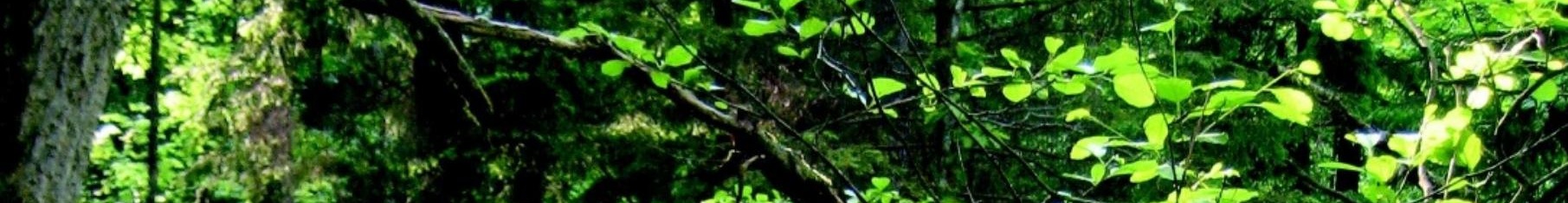

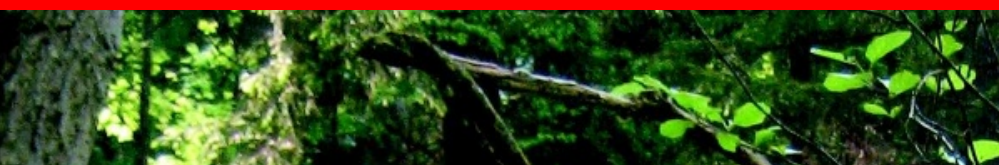

$\geq$

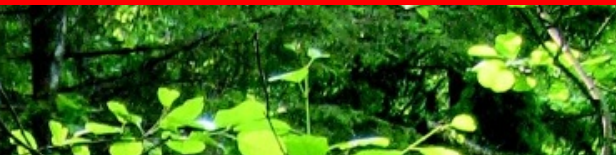

-

5

..

\section{+)}

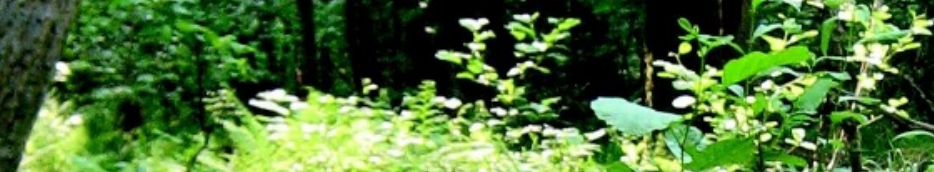

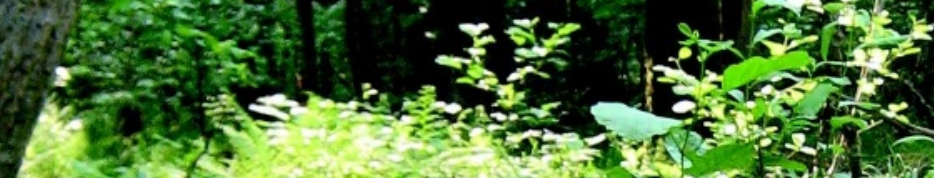

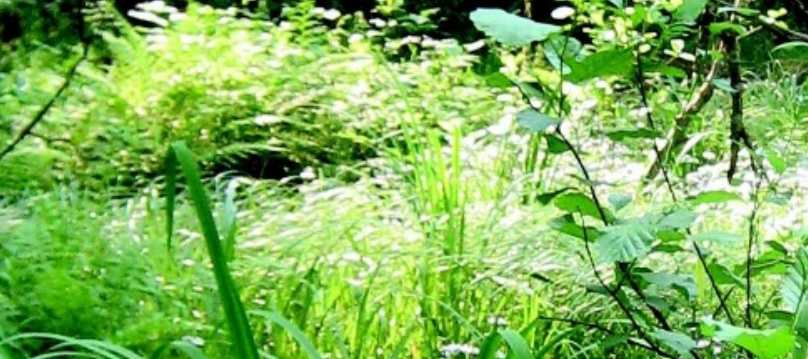

$x^{2}-120$ H. 

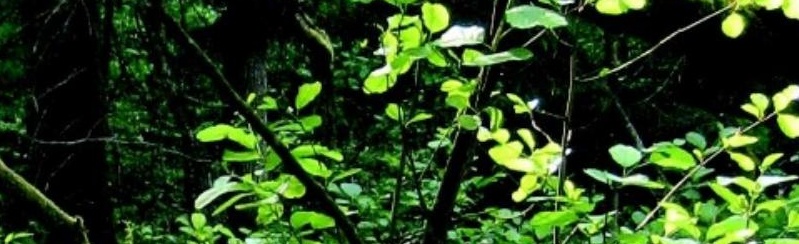

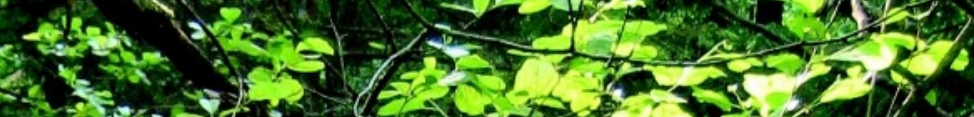

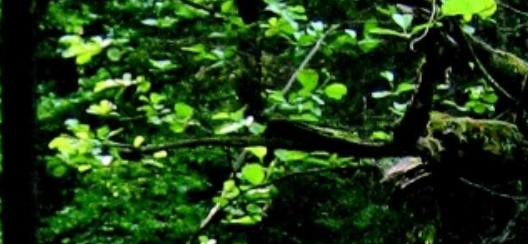

corest.

12.

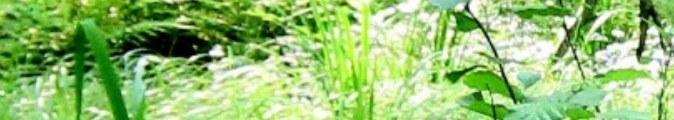

a

- 14

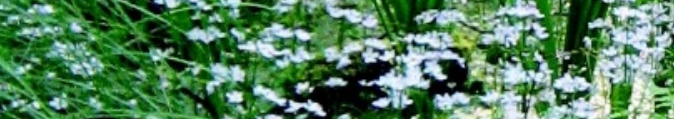

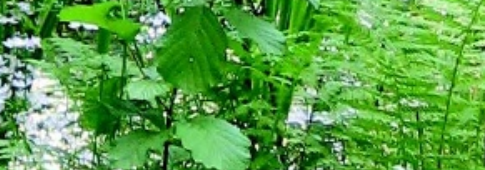

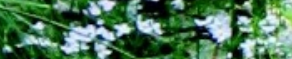

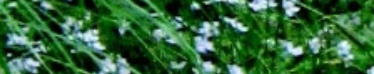

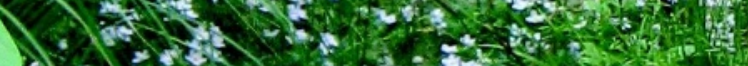

t.

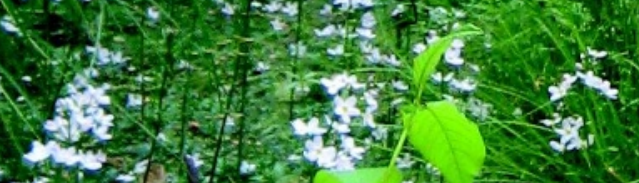

(2.

20.

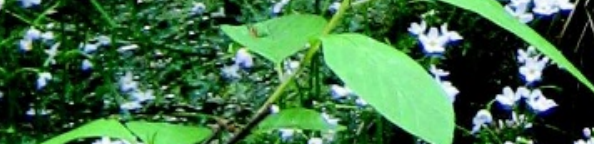

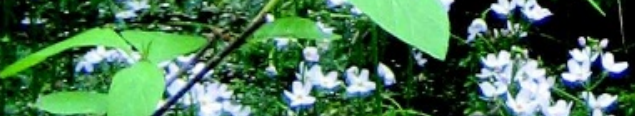

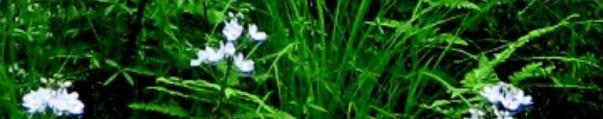

.

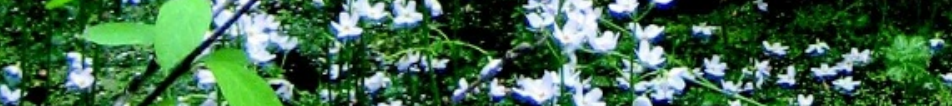

2n

$4)^{2}$

26 (x)

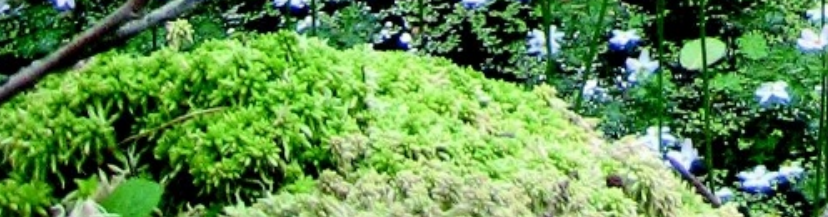

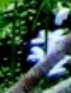

axe

30

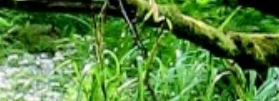

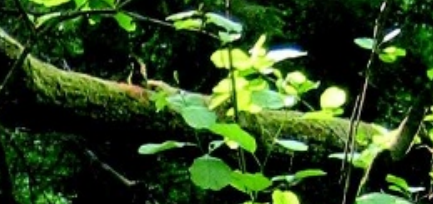

12

$5 y^{2}$ 


\section{Flora v. Fauna}

\begin{abstract}
Today there is virtually no management intervention in the Polish core of Białowieża. But the Parks Department, foresters and scientists disagree on how to manage the rest of the forest. The Parks Department intervenes more than the researchers at the Mammal Institute would recommend, feeding the bison in winter, for example, and culling them in summer.

"Most managers believe there are too many bison," says Rafal Kowalczyk of the Mammal Insitute as he races a truck down a forest road in pursuit of the signal from a radio-collared bison. (Over short distances he can track his charges by smell: "Not a smell as strong as wild boar or red deer. A bit like cattle; the smell of fresh milk.") Kowalczyk wants to stop culling and reduce winter feeding. "They survived for 1,000 years
\end{abstract}

without winter feeding," he says, "and I think densities could be higher." Małgorzata Karaś, director of Białowieża National Park disagrees, saying that the culling is done "according to the habitat capacity".

Kowalczyk thinks this habitat capacity is arbitrary. "There was a meeting in the 1960s and they

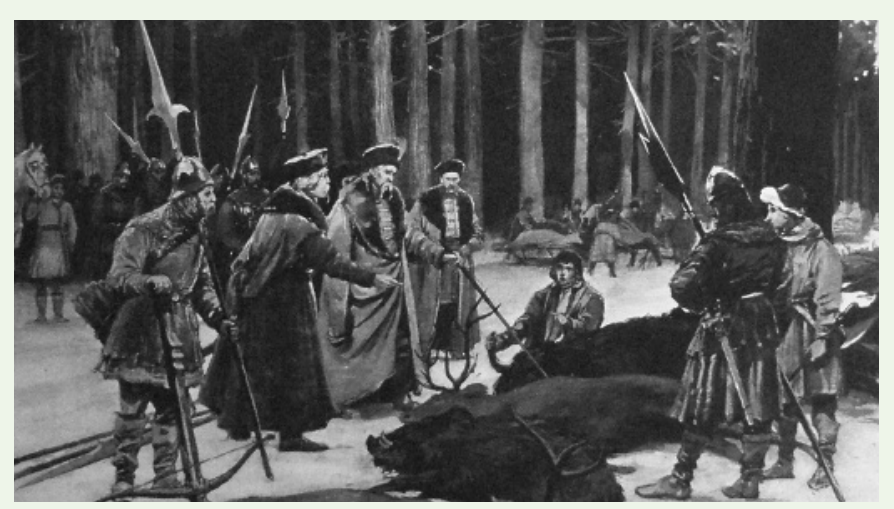

came up with 250 bison," he says. "It was a number taken from heaven." But foresters worry that more bison - the target is now 300 - would damage trees and prevent regeneration in parts of the forest used for timber.

Bogumiła Jedrzejewska, who joined the mammal institute in 1985 , says that communication sometimes be possible. Unfortunately, though, Białowieża faces a further handicap in this regard. To deal with change, an ecosystem needs space - to provide refuges for the species that will recolonize fire and wind clearings, room for ranges to change, and so on. Białowieża is quite small - only big enough, for example, for the 100-square-kilometre range of a single male lynx. "We have three or four, because ranges overlap, but hardly enough to sustain a population," says Jaroszewicz. The minimum size of a functioning forest probably varies greatly, but a calculation for Canadian boreal forest suggested about 650,000 hectares as the minimum size (S. J. Leroux et al. Biol. Conserv. 138, 464-473; 2007).

\section{Here and now}

But if neither present-natural nor original-natural, and with poor odds for becoming future-natural, Białowieża is still the best we have. For researchers looking for a proxy for European forests unchanged by modern man, Białowieża is a starting point; they still have to comb out the possible effects of human activity; to sort through tangled puzzles such as the spruce decline; to account for the small size of the forest and the changes in megafauna; and to race against the clock as climate change rearranges relationships.

In the end, it is the biological relationships which constitute the forest that are important to the science of ecology, not what history says about 'touched' and 'untouched'. History is uncertain: easily lost, written by victors, disproportionately concerned with the urban rich. Biology is available now, changing but measurable, and Białowieża has it in abundance. "Even if we estimate that 5,000 papers have been written about it, we still only know a little about it," says Jaroszewicz. "We still don't know what it will be in 100 years." The number of species, the complex interactions researchers track from year to year, and the individual trees, among the oldest and tallest in Europe, have a value beyond any question of whether they have been interfered with or not.

Wonder - formalized in science and experienced directly - trumps purity when it comes to feeling natural. Białowieża has long been human — but in a special and timeless way. Once, Samojlik found a sickle knife dropped by a previous visitor to the wood lying just under the tangled grass; it had been there for 1,500 years. Moss-hung and teeming with life, Białowieża retains one of the essential features of the European forest, at least as popularly imagined. It is still profoundly mysterious, even if it is no longer trackless or boundless.

Emma Marris writes for Nature from Columbia, Missouri. See Editorial, page 263.

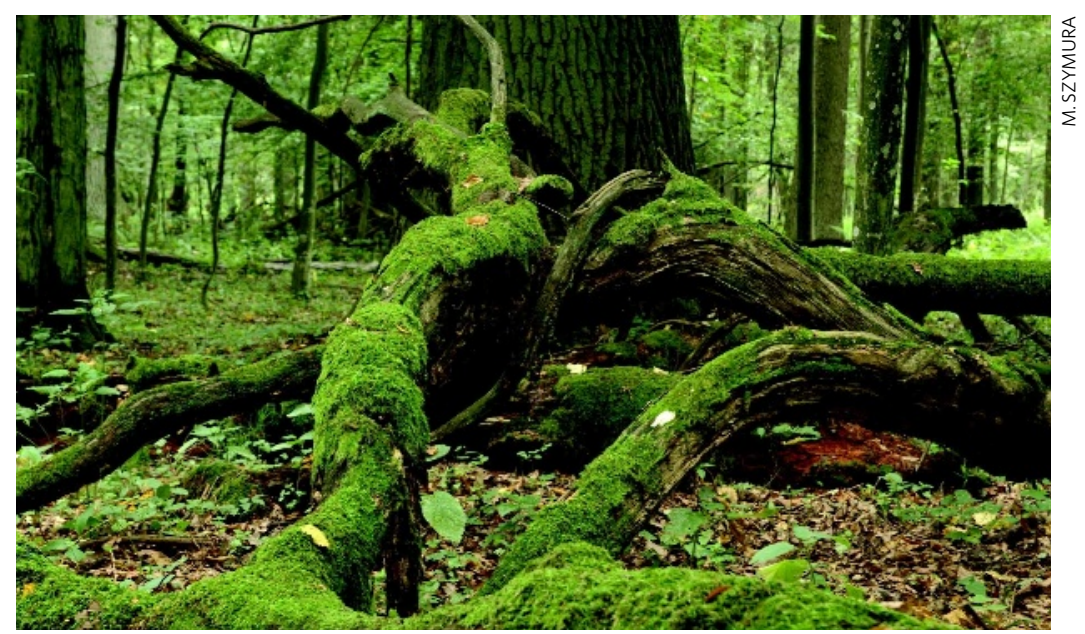

